Nat. Hazards Earth Syst. Sci., 20, 625-641, 2020

https://doi.org/10.5194/nhess-20-625-2020

(C) Author(s) 2020. This work is distributed under the Creative Commons Attribution 4.0 License.

\title{
Improved accuracy and efficiency of flood inundation mapping of low-, medium-, and high-flow events using the AutoRoute model
}

\author{
Michael L. Follum ${ }^{1,2}$, Ricardo Vera ${ }^{3}$, Ahmad A. Tavakoly ${ }^{1,4}$, and Joseph L. Gutenson ${ }^{1,5}$ \\ ${ }^{1}$ Coastal and Hydraulics Laboratory, Engineer Research and Development Center, \\ 3909 Halls Ferry Road, Vicksburg, MS 39180, USA \\ ${ }^{2}$ Wyoming Area Office, US Bureau of Reclamation, 705 Pendell Blvd., Mills, WY 82644, USA \\ ${ }^{3}$ Cold Regions Research and Engineering Laboratory, Engineer Research and Development Center, \\ 72 Lyme Road, Hanover, NH 03755, USA \\ ${ }^{4}$ Earth System Science Interdisciplinary Center, University of Maryland, College Park, MD 20740, USA \\ ${ }^{5}$ National Water Center, National Oceanic and Atmospheric Administration, 205 Hackberry Ln, Tuscaloosa, AL 35401, USA
}

Correspondence: Michael L. Follum (follumm@gmail.com)

Received: 6 June 2019 - Discussion started: 17 June 2019

Revised: 10 January 2020 - Accepted: 21 January 2020 - Published: 27 February 2020

\begin{abstract}
This article presents improvements and the development of a postprocessing module for the regional-scale flood mapping tool, AutoRoute. The accuracy of this model to simulate low-, medium-, and high-flow-rate scenarios is demonstrated at seven test sites within the US. AutoRoute is one of the tools used to create high-resolution flood inundation maps at regional to continental scales, but it has previously only been tested using extreme flood events. Modifications to the AutoRoute model and postprocessing scripts are shown to improve accuracy (e.g., average $F$ value increase of $17.5 \%$ for low-flow events) and computational efficiency (simulation time reduced by over $40 \%$ ) when compared to previous versions. Although flood inundation results for lowflow events are shown to be comparable with published values (average $F$ value of $63.3 \%$ ), the model results tend to be overestimated, especially in flatter terrain. Higher-flow scenarios tend to be more accurately simulated (average $F$ value of $77.5 \%$ ). With improved computational efficiency and the enhanced ability to simulate both low- and high-flow scenarios, the AutoRoute model may be well suited to provide firstorder estimates of flooding within an operational, regional- to continental-scale hydrologic modeling framework.
\end{abstract}

\section{Introduction}

Recent advances have demonstrated continental-scale flow forecasting models capable of simulating thousands of stream reaches simultaneously - e.g., National Water Model (NWM) (http://water.noaa.gov/about/nwm, last access: 14 February 2020) and Streamflow Prediction Tool (SPT) (Snow et al., 2016; Wahl, 2016). Although flow simulations at these scales are beneficial, water managers and emergency personnel benefit more from high-resolution flood inundation maps in making operational decisions (such as evacuation, road closures, etc.). Advanced hydraulic models typically operated from the reach scale to the small-basin scale have shown some success in simulating flood inundation at the continental scale (Wing et al., 2017) but at a high computational cost. Due to low data requirements, fast initial setup times, and lower computational burden, lowercomplexity hydraulic models have been developed in recent years to simulate flood inundation quickly using continentalscale hydrologic modeling outputs. Although not meant to replace the higher-fidelity hydraulic models, these lowercomplexity models can provide a reasonable first-order approximation of flood inundation over regional to continental extents and help prioritize where deployment of the higher-fidelity hydraulic models are needed (Follum et al., 2019). The National Oceanic and Atmospheric Administration (NOAA) National Water Center (NWC) has adopted the 
Height Above Nearest Drainage (HAND) model (Liu et al., 2018; Zheng et al., 2016) to use in conjunction with the NWM within the US. Due to a need for connecting hydrologic data to mobility models for the military, the US Army Coastal and Hydraulics Laboratory (CHL) developed the AutoRoute flood and mobility model (Follum, 2012; Follum et al., 2017; McKinley et al., 2012). AutoRoute works in conjunction with the SPT (Follum et al., 2017) to provide hydrologic and mobility guidance in data-sparse environments outside the continental United Stated (OCONUS). Currently SPT is run operationally ( $15 \mathrm{~d}$ streamflow forecasts updated twice daily) by CHL for approximately $70 \%$ of the world - between latitudes $\sim 54^{\circ} \mathrm{S}$ and $\sim 60^{\circ} \mathrm{N}$ based on data availability of the HydroSHEDS and HydroBASINS datasets (Lehner and Grill, 2013) from which SPT streamlines are derived. AutoRoute is currently operated in an ad hoc basis when flood inundation or mobility assessments are required.

Both HAND and AutoRoute are raster-based models. Using the high-resolution National Hydrography Dataset Plus (NHDPlus) dataset (Horizon Systems Corporation, 2007; McKay et al., 2012) and a $\sim 9 \mathrm{~m}$ digital elevation model (DEM), Liu et al. (2018) created HAND rasters for the entire US. A HAND raster simply shows the relative height of a cell above the nearest NHDPlus streamline (nearest in terms of drainage distance). Flow-depth rating curves are assigned to each stream reach (Zheng et al., 2018) so if given a flow rate the stage of the river can be calculated. Any HAND raster cell with a value less than the calculated river stage is considered flooded (inundated). However, this process relies heavily on precomputed flow-depth relationships currently not available for much of the world.

AutoRoute was initially developed by CHL to automatically develop cross sections along ephemeral streams/rivers to assess gap-crossing capabilities of military vehicles during flood events (Follum, 2012; McKinley et al., 2012). Because AutoRoute was utilized for ephemeral streams the channel profile (including bathymetry) was assumed to be represented by the DEM. Recently, AutoRoute has been applied with large-scale river routing models - such as the RAPID model (David et al., 2011; Tavakoly et al., 2017) within SPT - to simulate high-resolution $(<30 \mathrm{~m}$ spatial resolution) flood inundation maps over large extents: a $230000 \mathrm{~km}^{2}$ area in the midwestern US; a $109500 \mathrm{~km}^{2}$ area in the Mississippi Delta (Follum et al., 2017); the Sava river basin; Puerto Rico (Follum et al., 2018); the Navajo Nation (Follum et al., 2019); and Luzon, the Philippines (Wahl et al., 2016). Stream networks (polyline format) within the US are defined using the NHDPlus dataset. Outside the US, stream networks (polyline format) for approximately $70 \%$ of the world have been created using HydroSHEDS and HydroBASINS datasets (see Snow, 2015, for an example). AutoRoute converts the polyline stream locations to a raster or table format (see Follum et al., 2017, for details). Cross sections are automatically sampled for each stream cell from a DEM, and the normal depth is then calculated for a given flow rate us- ing Manning's equation. The extent and depth of flooding within the cross section is then mapped to a raster format. Only cells within the raster used for cross sections will show flood extent or depth. A postprocessing step is often utilized where flood extent results in raster format are converted to a polygon format. The main purpose of the postprocessing step is to overcome inaccuracies in the flood extents created by AutoRoute. Holes in the floodplain (cells not captured by cross sections) are filled, the boundaries along the floodplain are smoothed, and outliers in the flood extent (cells that show flooding where no other surrounding cells show flooding) are omitted. Outliers in the flood map are caused by large variations in flow depths along a given stream reach (Afshari et al., 2018; Follum et al., 2017), often caused by high elevation values due to bridges (Follum et al., 2017) or spikes in the DEM; cross sections not being sampled perpendicular to the stream channel; and errors in calculating the slope of the channel (related to errors in the stream network or DEM). It is expected that these variations in depth and flood extent will be more pronounced in low-flow events where differences in depth or inundation extent may be more evident in an inundation map. Computationally, the postprocessing step takes almost as long as the execution of the AutoRoute model itself (Follum et al., 2017). Additionally, this postprocessing step does not consider the terrain data; the postprocessing is used only to make flood inundation maps appear more continuous.

Afshari et al. (2018) compared HAND, AutoRoute (with postprocessing), and HEC-RAS 2D (USACE, 2016) at two locations: the Cedar River watershed in Iowa and the Black Warrior River in Alabama. Three statistical flow conditions were tested at each site: the 10-, 100-, and 500-year flow rates. The HAND and AutoRoute models produced similar flood inundation maps when compared to the moreadvanced HEC-RAS 2D model, but both HAND and AutoRoute showed less accuracy in meandering channels and near confluences. Overall, the AutoRoute model produced slightly higher flood extent accuracy than the HAND model. However, the AutoRoute model tended to have lower accuracy with lower-flow events. This highlights a concern that the AutoRoute model has typically been tested for large flood events - flood events greater than the 50-year flood were tested in Follum (2012), Follum et al. (2017, 2018, 2019), and Wahl et al. (2016) - and may not be applicable for lessextreme flow events.

This article presents modifications to the AutoRoute model to better incorporate bathymetry estimations and terrain in the calculation and postprocessing of flood inundation maps, which are expected to improve the flood mapping capability of the AutoRoute model for extreme (> 50-year flood event) and nonextreme flood cases. The modifications are expected to produce continuous and accurate flood extent results for both low- and high-flow events. The AutoRoute model is tested at seven locations within the US where flood inundation maps for multiple flow rate scenarios (ranging 
from low- to high-flow events) have been modeled and compared to observed flow events by NOAA's Advanced Hydrologic Prediction Service (McEnery et al., 2005).

\section{Methodology}

\subsection{AutoRoute model}

AutoRoute is a grid-based model where elevation, stream locations (stream cells), and land cover are defined using a raster format. Gridded stream cells were originally defined using a flow accumulation raster (Follum, 2012). With the creation of river networks in polyline format (e.g., NHDPlus and HydroSHEDS) stream cells are now created by converting polyline data to a raster or table format (table defines the $x$ and $y$ coordinates). Each stream cell retains the unique river reach identifier (e.g., ComID in NHDPlus) to associate attributes of the stream reach to each stream cell. For example, streamflow $Q\left(\mathrm{~m}^{3} \mathrm{~s}^{-1}\right)$ from a hydrologic model, such as SPT or NWM, is assigned to each stream cell using the river reach identifier. At each stream cell, cross sections are sampled from an elevation dataset (Fig. 1). In the original AutoRoute model the channel profile is estimated only from the elevation dataset; no bathymetric profile is assumed. Although not assuming a bathymetric profile was acceptable in the original applications of AutoRoute where ephemeral streams were being simulated, AutoRoute is being used in more regions, and the inclusion of bathymetric profiles should improve flood inundation estimations (Dey et al., 2019) and mobility assessments. For each cross section sampled, AutoRoute now includes a bathymetry estimation. AutoRoute adjusts the centerline of the cross section to the lowest point. The lateral distance that AutoRoute searches for the lowest point is specified by the user, typically defined as $20 \mathrm{~m}$. As shown in Fig. 1, the cross section sampled from the DEM often shows the stream/river as a flat surface. AutoRoute automatically finds the top width $(T, \mathrm{~m})$ of the water surface and then estimates a bathymetric profile. The bathymetric profile is assumed to have an exponential shape, as shown in Fig. 1. The exponential shape takes the form

$y=\delta|x|^{\beta}$,

where $y(\mathrm{~m})$ and $x(\mathrm{~m})$ are the ordinates of the bathymetric profile as shown in Fig. 1 and $\delta$ is a user-defined parameter (assumed 0.001 for this paper). When $x=0$ the maximum depth of the bathymetric profile $(Z, \mathrm{~m})$ is assumed to occur ( $y=0$ based on the orientation of the $y$ and $x$ axes in Fig. 1). When $x=T / 2$ the bathymetric profile is at the bank of the river and $y=Z$. Based on these two constraints and Eq. (1), $\beta$ is calculated as

$\beta=\frac{\log (Z / \delta)}{\log (T / 2)}$.

Using Manning's equation (described below), $Z$ is calculated so that a specified base flow will pass through the bathy- metric profile. The bathymetric profile is burned into the cross-section profile and the centerline of the stream/river is again adjusted to the lowest point. Hydraulic area $A\left(\mathrm{~m}^{2}\right)$ and wetted perimeter $P(\mathrm{~m})$ are calculated at each cross section for a given flow depth $D(\mathrm{~m})$. Using a volume-fill approach, $D$ is incrementally increased until there is less than a $1 \%$ difference between $Q$ and the calculated streamflow $Q_{\text {calc }}\left(\mathrm{m}^{3} \mathrm{~s}^{-1}\right)$, calculated using Manning's equation:

$Q_{\text {calc }}=\frac{c_{\mathrm{u}}}{n} A^{5 / 3} P^{-2 / 3} S_{f}^{1 / 2}$,

where $c_{u}$ is the unit constant (1.0 for metric units), $n$ is the Manning roughness coefficient, and $S_{f}$ is the hydraulic slope. Normal depth is assumed, and therefore $S_{f}=S_{o}$, where $S_{o}$ is the slope of the channel. AutoRoute calculates $S_{o}$ by analyzing the elevations and lateral distances upstream and downstream of the stream cell being analyzed (more explanation found in Follum et al., 2017). $n$ is estimated as (Horton, 1933; Einstein, 1934)

$n=\left[\sum_{i=1}^{N} \frac{P_{i} n_{i}{ }^{1.5}}{P}\right]^{2 / 3}$,

where $P_{i}$ and $n_{i}$ are the wetted perimeter and Manning roughness coefficient of the $i$ th segment within the cross section, and $N$ is the total number of segments within the cross section that are flooded. $n_{i}$ values are associated with land cover types, as described in Follum et al. (2017).

An initial cross section is sampled perpendicular to the stream direction, as defined by positions of upstream and downstream stream cells. However, stream cross sections may not always adequately capture the floodplain geometry; therefore multiple cross sections are sampled for each stream cell by incrementally pivoting the cross section relative to the stream direction. As shown in Follum et al. (2017), these multiple cross sections have the effect of filling in the floodplain but can also create errant cross sections and therefore errors in the floodplain mapping. The cross section for each stream cell (subscript "sc") that produces the shortest top width $\mathrm{TW}_{\mathrm{sc}}(\mathrm{m})$ is expected to be the most representative cross section for that stream cell. The $\mathrm{TW}_{\mathrm{sc}}$ and the flow depth $D_{\mathrm{sc}}(\mathrm{m})$ of the representative cross section are recorded for each stream cell.

AutoRoute originally created flood inundation and flood depth rasters by mapping all of the cross-section depths and extents onto a raster (Follum, 2012). Later, an iterative combination of the Boundary Clean and Aggregate Polygons functions within ArcGIS (ESRI, 2011) was then used to fillin holes, omit outlier flood cells, and smooth boundaries along the flood polygon (Follum et al., 2017). None of the previous postprocessing considered topography in the creation of the flood polygon. In this paper the use of Boundary Clean and Aggregate Polygons functions within ArcGIS (ESRI, 2011) is considered the baseline method for postprocessing AutoRoute results and is referred to as GIS postprocessing (GISPP). 

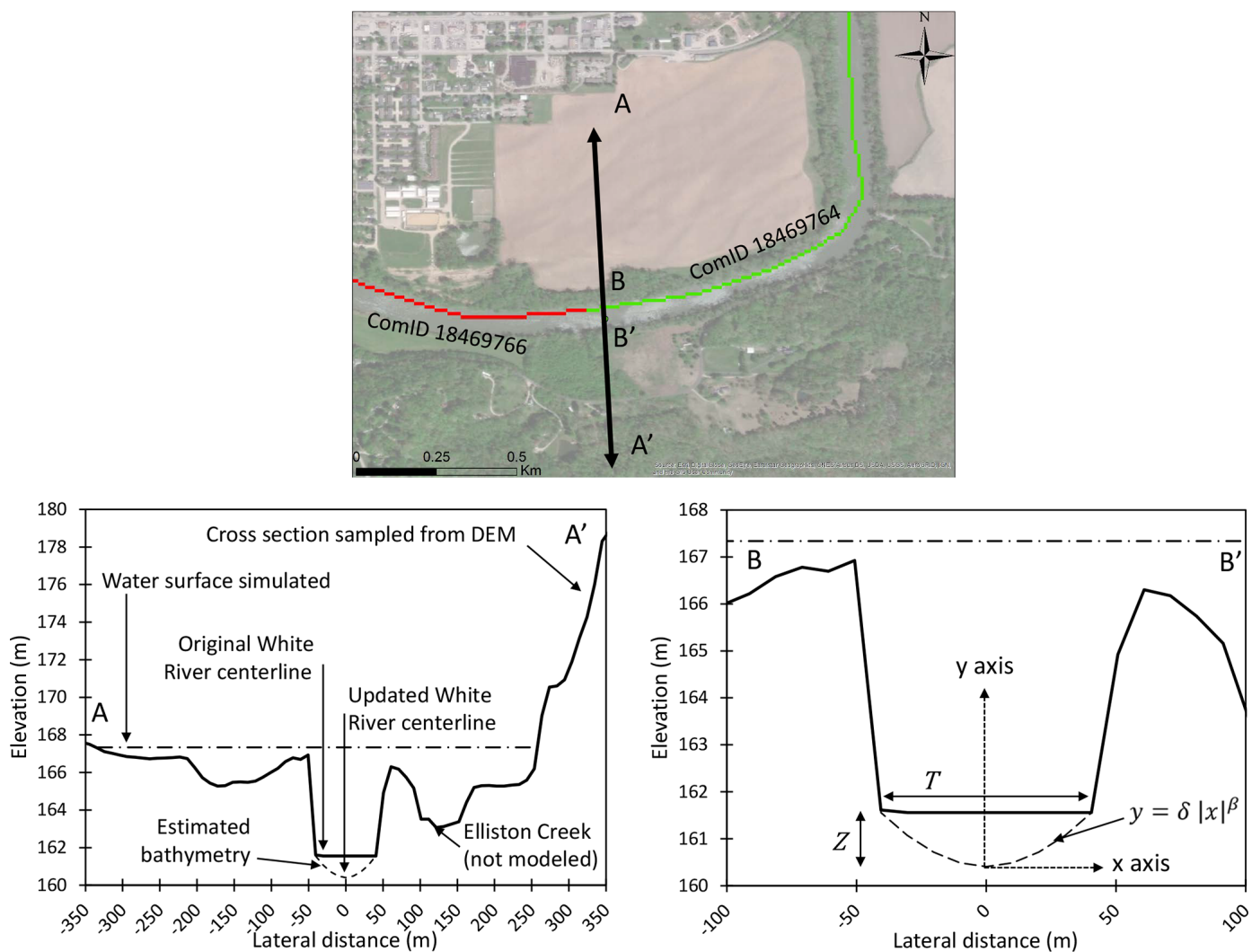

Figure 1. Cross-section profile of the White River near Spencer, IN. Also shown is the bathymetry estimation where $T$ is the top width of the channel, $Z$ is the maximum depth of the bathymetry profile, and $y$ and $x$ are the ordinates of the bathymetry profile. Sources of the background imagery include ESRI, DigitalGlobe, Earthstar Geographics, CNES/Airbus DS, GeoEye, USDA FSA, USGS, Getmapping, Aerogrid, IGN, IGP, and the GIS user community.

\subsection{Development of the AutoRoute postprocessing script (ARPP)}

The AutoRoute postprocessing script (ARPP) has been developed to better account for topography when creating the flood inundation map. The water surface elevation of each stream cell $\left(\mathrm{WSE}_{\mathrm{sc}}, \mathrm{m}\right)$ is calculated as

$\mathrm{WSE}_{\mathrm{sc}}=E_{\mathrm{c}}+D_{\mathrm{sc}}$

where $E_{\mathrm{c}}(\mathrm{m})$ is the elevation of the cell. The water surface elevation for each cell in the model domain $\left(\mathrm{WSE}_{\mathrm{c}}, \mathrm{m}\right)$ is interpolated from the $\mathrm{WSE}_{\mathrm{sc}}$ values using inverse-distance weighting:

$\mathrm{WSE}_{\mathrm{c}}=\frac{\sum \mathrm{WSE}_{\mathrm{sc}} w}{\sum w}$,

where $w$ is the weight, calculated as

$\left\{\begin{array}{lll}w=d_{\mathrm{c} \rightarrow \mathrm{sc}}^{-2} & \text { if } & d_{\mathrm{c} \rightarrow \mathrm{sc}} \leq \alpha \mathrm{TW}_{\mathrm{sc}} \\ w=0 & \text { if } & d_{\mathrm{c} \rightarrow \mathrm{sc}}>\alpha \mathrm{TW}_{\mathrm{sc}}\end{array}\right.$

where $d_{\mathrm{c} \rightarrow \mathrm{sc}}(\mathrm{m})$ is the distance between the model domain cell and the stream cell, and $\alpha$ is a user-defined parameter.
Higher values of $\alpha$ increase the influence that each stream cell has on flooding the surrounding cells. The flood depth for each cell in the domain $D_{\mathrm{c}}(\mathrm{m})$ is then calculated as

$D_{\mathrm{c}}=\mathrm{WSE}_{\mathrm{c}}-E_{\mathrm{c}}$,

where $D_{\mathrm{c}}$ values less than zero are set to zero and cells with $D_{\mathrm{c}}$ values greater than zero are considered flooded. All flooded cells are then converted to a polygon format.

Figure 2 a demonstrates the flooding ( $D_{\mathrm{c}}$ values) of the surrounding terrain from a single stream cell. When the depths from all stream cells are included by use of Eqs. (6) and (7) the flooding of the surrounding cells provides a continuous flood map with holes only in the high-elevation areas (Fig. 2b). Additionally, stream cells that have $\mathrm{WSE}_{\mathrm{sc}}$ values higher/lower than surrounding stream cells (i.e., outliers) have an impact only on the immediately surrounding cells (see shallow locations within river in Fig. 2b). These outliers can be caused by cross sections not being perpendicular to the stream reach, errors in hydraulic slope estimation, and errors within the DEM. Although these outliers affect the immediately surrounding cells, they have minimal impact on flooding in the floodplain. However, these outliers could affect channel profiles for mobility analysis and should be ad- 




Figure 2. Panel (a) shows flood depths of surrounding terrain from a single stream cell. Notice the area of influence (cells within radius $=\alpha \mathrm{TW}_{\mathrm{sc}}$ ) appears elliptical due to projection of the map. Panel (b) shows flood depths along the river when the depths from all stream cells are utilized. Notice that some areas shown as flooded in (a) are not flooded in (b) due to the influence of stream cells with lower depth calculations. Sources of the background imagery include ESRI, DigitalGlobe, Earthstar Geographics, CNES/Airbus DS, GeoEye, USDA FSA, USGS, Getmapping, Aerogrid, IGN, IGP, and the GIS user community.

dressed in future research. The minimal impact of outliers on flood inundation is due to the influence of water surface elevations from multiple stream cells on each $\mathrm{WSE}_{\mathrm{c}}$ value. Use of ARPP to postprocess AutoRoute flood depth results is expected to produce more continuous flood maps, account for topography, and reduce the impact of errant $D_{\mathrm{sc}}$ values on the flood inundation results, all of which are expected to be important in simulating both low- and high-flow events.

\subsection{Study locations}

For several communities throughout the United States the US Geological Survey (USGS) has created flood inundation maps for multiple water surface elevations (stages) of the river. These maps are intended to be used in conjunction with National Weather Service (NWS) forecasted peak-stage data to show predicted areas of flooding. The modeled stage heights vary between the sites but are intended to capture the river stage at multiple (often around 20) stages between normal conditions (low flow) and the highest rated stage at the streamgage (high flow). The hydraulic model used to create the flood inundation maps varies between the sites, but each model is validated against observed flood events. For this study seven locations where the USGS has completed flood inundation studies were chosen (Fig. 3). Each site varies in complexity as well as geographical location (multiple river basins throughout the US).

For each site used in this study Table 1 lists the location, identification (ID), river(s), USGS streamgage number, length of river segments within the study, and reference. All studies utilized lidar elevation datasets ranging between 0.9 and $3 \mathrm{~m}$ horizontal spatial resolution. The HEC-RAS hydraulic model (USACE, 2010, 2016) was used in each study and was calibrated and validated to observed flood data.

Table 2 lists the base flow and the low, medium, and high flow rates used in the study. The low, medium, and high flow rates were chosen based on the minimum, median, and maximum modeled flow rates in each of the USGS studies (a flow rate was assigned to each stage height in each of the studies). The USGS does not provide base flow estimates for the sites in this study, so the base flow was estimated as the average annual flow rate for each gage listed in Table 1 . The annual flow rates were obtained from USGS WaterWatch (https: //waterwatch.usgs.gov/?id=ww_current; last access: 1 February 2019). The USGS streamgage 02126375 along the Pee Dee River (Fig. 8) does not record flow rates, so the flow data from the USGS streamgage 0212378405 approximately $12 \mathrm{~km}$ upstream along the Pee Dee River was used to estimate baseflow. Brown Creek and Rocky River are also included in the NC study (Smith and Wagner, 2016) but are omitted from this study because flow rates were unavailable. The USGS streamgage 02473000 along the Leaf River is used in the MS study and is less than $1 \mathrm{~km}$ downstream of the confluence of the Leaf and Bouie rivers (Fig. 9). Above the confluence of the rivers the Leaf and Bouie rivers are assumed to carry approximately $70 \%$ and $30 \%$, respectively, of the flow rates measured at the USGS streamgage 02473000 (Storm, 2014).

\section{Model application}

AutoRoute models were developed for each of the seven test locations. Each model was developed using elevation data from the $1 / 3 \operatorname{arcsec}(\sim 9 \mathrm{~m})$ National Elevation 


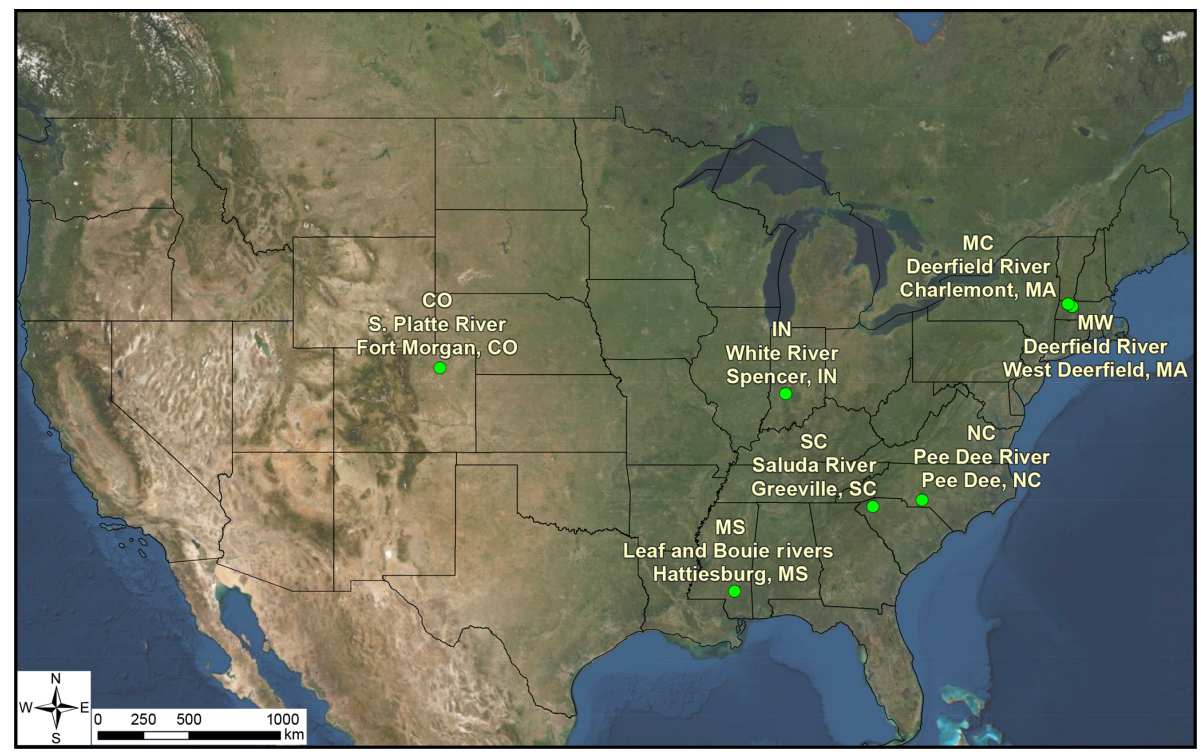

Figure 3. USGS study sites used in this study. For each study site the location, ID, and river(s) are provided. Sources of the background imagery include ESRI, DigitalGlobe, Earthstar Geographics, CNES/Airbus DS, GeoEye, USDA FSA, USGS, Getmapping, Aerogrid, IGN, IGP, and the GIS user community.

Table 1. USGS study sites used in this study. For each study site the location, ID, river(s), USGS streamgage, model length, and reference are provided.

\begin{tabular}{lllrrl}
\hline Location & ID & River(s) & $\begin{array}{c}\text { USGS } \\
\text { streamgage } \\
\text { number }\end{array}$ & $\begin{array}{r}\text { Model } \\
\text { length } \\
(\mathrm{km})\end{array}$ & Reference \\
\hline Spencer, IN & IN & White River & 03357000 & 8.5 & Nystrom (2013) \\
Fort Morgan, CO & CO & S. Platte River & 06759500 & 7.2 & Kohn and Patton (2018) \\
Greenville, SC & SC & Saluda & 02162500 & 6.4 & Benedict et al. (2013) \\
Pee Dee, NC & NC & Pee Dee River & 02126375 & 17.0 & Smith and Wagner (2016) \\
Hattiesburg, MS & MS & Leaf and Bouie rivers & 02473000 & 10.9 & Storm (2014) \\
Charlemont, MA & MC & Deerfield River & 01168500 & 14.6 & Lombard and Bent (2015) \\
West Deerfield, MA & MW & Deerfield River & 01170000 & 14.3 & Lombard and Bent (2015) \\
\hline
\end{tabular}

Dataset (NED; Gesch et al., 2002), and land cover classifications were obtained from the 2011 National Land Cover Database (NLCD) (Homer et al., 2015). The NLCD has a spatial resolution of approximately $30 \mathrm{~m}$ and therefore was resampled to the resolution of the DEM. The stream networks for each study site were defined using the NHDPlus dataset.

For each simulation, the quantitative performance of the AutoRoute models compared to the USGS data is measured using the $F$ statistic ( $F$, percentage) (Bates and De Roo, 2000; Tayefi et al., 2007) and error bias (E) (Wing et al., 2017):

$F=100\left(\frac{A_{\mathrm{Acc}}}{A_{\mathrm{Obs}}+A_{\mathrm{Sim}}-A_{\mathrm{Acc}}}\right)$,
$E=\frac{A_{\text {Over }}}{A_{\text {Under }}}$,

where $A_{\mathrm{Obs}}\left(\mathrm{km}^{2}\right)$ is the area of flooding from the USGS flood maps, $A_{\text {Sim }}\left(\mathrm{km}^{2}\right)$ is the area of flooding from the AutoRoute simulation, $A_{\mathrm{Acc}}\left(\mathrm{km}^{2}\right)$ is the area where both $\mathrm{Au}$ toRoute and the USGS show flooding, $A_{\text {Over }}\left(\mathrm{km}^{2}\right)$ is the area where only the AutoRoute model shows flooding, and $A_{\text {Under }}\left(\mathrm{km}^{2}\right)$ is the area where only the USGS flood maps shows flooding. $F$ ranges between $0 \%$ and $100 \%$, with a value of $100 \%$ indicating a perfect fit between the AutoRoute and USGS flood inundation maps. Previous applications of AutoRoute within the US have had $F$ values between $58.4 \%$ and $92.5 \%$ (Follum et al., 2017), with the IN test site having an $F$ value of $77 \%$ when compared to observed flood 
Table 2. Base flow and low, medium, and high flow rates for each study site.

\begin{tabular}{lrrrr}
\hline ID & $\begin{array}{r}\text { Base } \\
\text { flow } \\
\left(\mathrm{m}^{3} \mathrm{~s}^{-1}\right)\end{array}$ & $\begin{array}{r}\text { Low } \\
\left(\mathrm{m}^{3} \mathrm{~s}^{-1}\right)\end{array}$ & $\begin{array}{r}\text { Medium } \\
\left(\mathrm{m}^{3} \mathrm{~s}^{-1}\right)\end{array}$ & $\begin{array}{r}\text { High } \\
\text { flow } \\
\left(\mathrm{m}^{3} \mathrm{~s}^{-1}\right)\end{array}$ \\
\hline IN & 83.9 & 164.0 & 577.7 & 2027.5 \\
CO & 16.6 & 79.9 & 577.7 & 2814.7 \\
SC & 17.2 & 79.6 & 222.9 & 373.8 \\
NC & 145.4 & 911.8 & 3021.1 & 7391.8 \\
MS & 63.5 & 999.6 & 1730.2 & 3409.3 \\
MC & 25.9 & 311.5 & 996.8 & 2415.4 \\
MW & 38.2 & 455.9 & 1659.4 & 3344.2 \\
\hline
\end{tabular}

maps from the June 2008 flood. $E$ ranges between 0 and $\infty$ with $E$ values less than 1 indicating a bias towards underestimation, $E$ values greater than 1 indicating a bias towards overestimation, and an $E$ value of 1 indicating no bias.

The AutoRoute model has few calibration parameters. Following Follum et al. (2017), $n_{i}$ values were set to the lower bound as described in Moore (2011), Chow (1959), and Calenda et al. (2005). The number of cross sections sampled at each stream cell was set to 9 following Follum et al. (2017). The influence that each stream cell has on flooding the surrounding cells is controlled by the user-defined $\alpha$ parameter. A sensitivity analysis was performed to determine the affect $\alpha$ has on the flood inundation when using ARPP postprocessing. Using all seven test sites and all three flow scenarios $\alpha$ was varied between 0.25 and 3.0 by increments of 0.25 . Figure 4 shows the $F$ value associated with each of the 252 simulations. Increases in $\alpha$ tend to result in an increase in accuracy (higher $F$ values). However, increases in $\alpha$ also increase the computational burden. For example, 4 times as many cells are analyzed for each stream cell when $\alpha=3.0$ than when $\alpha=1.5$. For this study $\alpha$ is set to 1.5 because it provides good coverage of the river floodplain (and thus higher $F$ values) while remaining computationally efficient.

\section{Results and discussion}

\subsection{Flood inundation mapping}

For each study site the low-, medium-, and high-flow scenarios were simulated using AutoRoute. The results were then postprocessed using the ARPP method (AutoRoute + ARPP) described in this paper as well as the original GISPP method (AutoRoute + GISPP). The only difference between AutoRoute + GISPP and AutoRoute + ARPP results is the postprocessing method used. For each test case Table 3 shows the quantitative performance ( $F$ and $E$ ) of flood inundation maps simulated using AutoRoute+ARPP and Au-

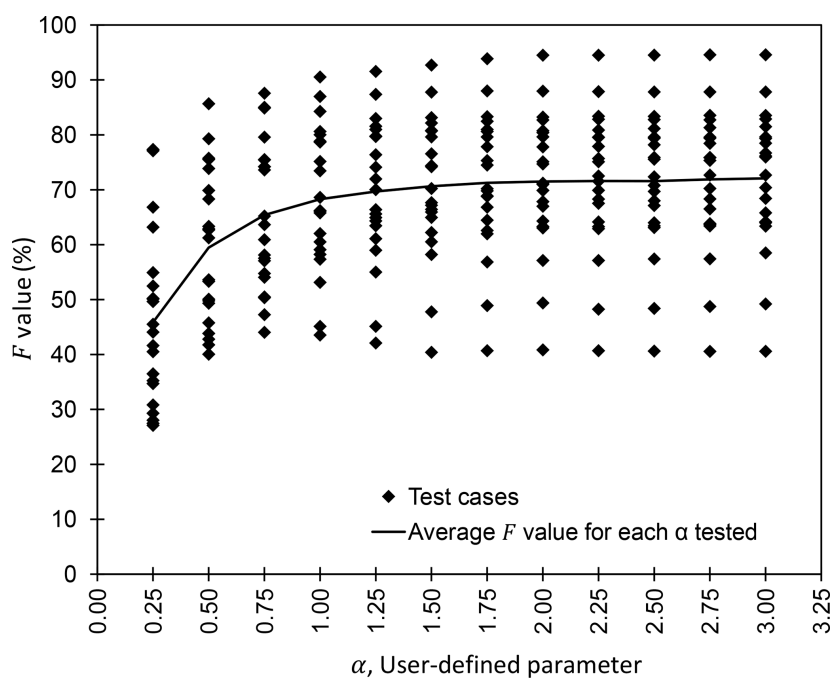

Figure 4. Sensitivity analysis of the user-defined parameter $\alpha$, which controls the influence that each stream cell has on flooding the surrounding cells when using ARPP postprocessing. $F$ statistic $(F$, percentage) values calculated using the observed and simulated flood inundation areas are plotted against the $\alpha$ value used in the simulation. In total, 252 simulations are shown (seven test sites, three flow scenarios, and $12 \alpha$ values).

toRoute + GISPP as compared to the USGS flood inundation maps. Table 3 also shows the value of $A_{\mathrm{Obs}}, A_{\mathrm{Sim}}$, $A_{\text {Over }}, A_{\text {Under }}$, and $A_{\text {Acc }}$ for each flood inundation map simulated using AutoRoute+ARPP. Overall, the use of ARPP results improved flood inundation accuracy when compared to GISPP (average $F$ value is $7.4 \%$ higher when using ARPP). The increase in accuracy of the ARPP method is most evident in the low-flow scenarios where the average $F$ value increases from $45.8 \%$ when using GISPP to $63.3 \%$ when using ARPP. For the medium-flow scenarios the average $F$ value increases from $65.7 \%$ when using GISPP to $70.0 \%$ when using ARPP. The difference in $F$ value for the highflow scenario is minimal when using GISPP $(77.2 \%)$ and ARPP $(77.5 \%)$. Flooding results are split between overestimation $(E>1)$ and underestimation $(E<1)$ when using the ARPP method (10 test cases underestimated and 11 test cases overestimated), while the GISPP method is more prone to overestimation ( 6 test cases underestimated and 15 test cases overestimated). Overall, the use of ARPP improved the accuracy (higher $F$ value) of the flood results in 18 of the 21 test cases.

Figures 5-7 show a comparison between flood inundation maps generated using AutoRoute + ARPP and the USGS flood maps. In the figures the areas shaded green (Accurate) indicate areas where AutoRoute + ARPP and the USGS flood maps agree. Areas shaded red (Over) indicate where only AutoRoute+ARPP simulates the area as flooded, and areas shaded blue (Under) indicate where only the USGS shows the area as flooded. The accuracy of the flood maps 
Table 3. $F$ statistic ( $F$, percentage) and error bias $(E)$ for AutoRoute + ARPP and AutoRoute + GISPP for each flow scenario at all seven test location. Inundation coverage areas $\left(A_{\mathrm{Obs}}, A_{\mathrm{Sim}}, A_{\mathrm{Over}}, A_{\mathrm{Under}}\right.$, and $\left.A_{\mathrm{Acc}}\right)$ are also shown for AutoRoute + ARPP. $F$ ranges between $0 \%$ and $100 \%$, with a value of $100 \%$ indicating a perfect fit between the simulated and USGS flood inundation maps. $E$ values less than 1 indicate a bias towards underestimation, $E$ values greater than 1 indicate a bias towards overestimation, and an $E$ value of 1 indicates no bias. All inundation coverage areas have units of square kilometers $\left(\mathrm{km}^{2}\right) . F, E$, and inundation coverage areas are also shown for the two sites tested using higher-resolution elevation data (MS-3m and NC-3m).

\begin{tabular}{|c|c|c|c|c|c|c|c|c|c|c|}
\hline \multirow[b]{2}{*}{ Location } & \multirow[b]{2}{*}{$\begin{array}{l}\text { Flow } \\
\text { rate }\end{array}$} & \multicolumn{7}{|c|}{ AutoRoute + ARPP } & \multicolumn{2}{|c|}{ AutoRoute + GISPP } \\
\hline & & $A_{\mathrm{Obs}}$ & $A_{\text {Sim }}$ & $A_{\text {Over }}$ & $A_{\text {Under }}$ & $A_{\text {Acc }}$ & $F$ & $E$ & $F$ & $E$ \\
\hline \multirow{3}{*}{ IN } & Low & 0.75 & 0.91 & 0.18 & 0.02 & 0.72 & 78.2 & 8.22 & 54.9 & 37.74 \\
\hline & Medium & 2.36 & 2.89 & 0.86 & 0.33 & 2.03 & 63.0 & 2.60 & 52.5 & 5.81 \\
\hline & High & 5.48 & 4.66 & 0.10 & 0.92 & 4.56 & 81.7 & 0.11 & 78.4 & 0.54 \\
\hline \multirow{3}{*}{$\mathrm{CO}$} & Low & 0.71 & 0.66 & 0.13 & 0.18 & 0.53 & 63.1 & 0.70 & 53.1 & 3.19 \\
\hline & Medium & 2.68 & 1.89 & 0.14 & 0.93 & 1.75 & 62.2 & 0.15 & 59.0 & 2.04 \\
\hline & High & 6.67 & 5.87 & 0.17 & 0.97 & 5.69 & 83.2 & 0.18 & 80.9 & 0.40 \\
\hline \multirow{3}{*}{$\mathrm{SC}$} & Low & 0.26 & 0.30 & 0.07 & 0.03 & 0.23 & 71.6 & 2.59 & 42.7 & 53.14 \\
\hline & Medium & 0.63 & 0.51 & 0.08 & 0.20 & 0.43 & 60.6 & 0.39 & 59.1 & 4.33 \\
\hline & High & 0.97 & 0.70 & 0.04 & 0.31 & 0.66 & 65.9 & 0.12 & 75.8 & 1.41 \\
\hline \multirow{3}{*}{$\mathrm{NC}$} & Low & 3.65 & 7.82 & 4.58 & 0.42 & 3.23 & 39.3 & 10.97 & 27.7 & 15.43 \\
\hline & Medium & 20.27 & 20.48 & 0.89 & 0.67 & 19.60 & 92.6 & 1.32 & 87.0 & 1.55 \\
\hline & High & 25.69 & 23.34 & 0.43 & 2.78 & 22.91 & 87.7 & 0.15 & 86.5 & 0.31 \\
\hline \multirow{3}{*}{ MS } & Low & 6.45 & 9.78 & 4.66 & 1.33 & 5.12 & 46.1 & 3.49 & 42.2 & 4.91 \\
\hline & Medium & 14.40 & 12.59 & 1.71 & 3.52 & 10.88 & 67.6 & 0.49 & 65.9 & 0.80 \\
\hline & High & 21.46 & 16.98 & 1.13 & 5.61 & 15.85 & 70.2 & 0.20 & 68.9 & 0.60 \\
\hline \multirow{3}{*}{$\mathrm{MC}$} & Low & 1.26 & 1.39 & 0.21 & 0.08 & 1.18 & 80.0 & 2.62 & 57.3 & 24.96 \\
\hline & Medium & 2.18 & 2.39 & 0.41 & 0.19 & 1.99 & 76.7 & 2.10 & 57.9 & 6.31 \\
\hline & High & 3.42 & 3.73 & 0.55 & 0.25 & 3.18 & 80.0 & 2.25 & 67.1 & 6.95 \\
\hline \multirow{3}{*}{ MW } & Low & 1.76 & 1.77 & 0.38 & 0.37 & 1.39 & 65.0 & 1.02 & 43.0 & 8.97 \\
\hline & Medium & 6.91 & 4.97 & 0.19 & 2.12 & 4.79 & 67.5 & 0.09 & 78.3 & 1.14 \\
\hline & High & 8.57 & 6.93 & 0.34 & 1.98 & 6.59 & 74.0 & 0.17 & 83.0 & 0.99 \\
\hline \multirow{3}{*}{ MS-3m } & Low & 6.45 & 5.18 & 1.56 & 2.83 & 3.62 & 45.2 & 0.55 & & \\
\hline & Medium & 14.40 & 9.90 & 1.10 & 5.59 & 8.81 & 56.8 & 0.20 & & \\
\hline & High & 21.46 & 16.41 & 0.66 & 5.71 & 15.75 & 71.2 & 0.12 & & \\
\hline \multirow{3}{*}{$\mathrm{NC}-3 \mathrm{~m}$} & Low & 3.65 & 7.75 & 4.53 & 0.42 & 3.23 & 39.5 & 10.69 & & \\
\hline & Medium & 20.27 & 20.68 & 0.90 & 0.48 & 19.79 & 93.5 & 1.86 & & \\
\hline & High & 25.69 & 23.39 & 0.42 & 2.72 & 22.97 & 88.0 & 0.15 & & \\
\hline
\end{tabular}

generated using low flows (average $F$ value of $63.3 \%$ ) is comparable with results from other studies (Afshari et al., 2018; Dey et al., 2019; Follum et al., 2017; Tayefi et al., 2007 ) but tends to overestimate flooding (all $E$ values are greater than 1 except for the $\mathrm{CO}$ test site). Although IN has the highest $E$ value, the high $F$ value and Fig. 5 show the flood map during the low-flow event is accurately simulated and the $E$ value is inflated due to the minimal underestimation of flooding (Table 3). Visually and quantitatively, NC and MS (Fig. 5 and Table 3) have the greatest amount of overestimation during the low-flow event, resulting in the lowest $F$ values of all the simulations. NC shows overestimation in low-lying areas adjacent to the river where the ARPP al- lows for flooding in areas even if they are not hydraulically connected to the streamlines, resulting in the lowest overall $F$ value of $39.3 \%$. MS also shows gross overestimation of flooding during the low-flow event. MS has minimal topography, a characteristic that has shown AutoRoute to produce less accurate results (Follum et al., 2017). AutoRoute simulations are essentially one-dimensional (1-D); better representation of hydrodynamics in areas with minimal topography occurs with multidimensional modeling. Additionally, MS has the highest ratio of low flow to base flow (the low flow used in this study is over 15 times the flow rate of the base flow), which may have led to errors in bathymetry estimation if the elevation dataset was derived during a higher- 
flow event. The coarse resolution used in this study compared to the USGS study may also contribute to inaccuracies (e.g., overestimation) that may be more pronounced in flatter terrain such as MS. While most streams considered in this analysis lie in rural land use environments, such as forested or agricultural areas, MS occurs in a primarily urban to suburban environment where small-scale changes in the topography are smoothed or negated in the relatively coarse $\sim 9 \mathrm{~m}$ DEM. Many of these missed topographic features are likely flood control structures, such as levees. The combination of minimal topography, DEM inaccuracies, and land use complexities likely led to the overestimation found in the MS study.

With a few exceptions (e.g., SC), the flood maps generated for the medium-flow events ( $F$ value of $70.0 \%$; Fig. 6$)$ and high-flow events ( $F$ value of $77.5 \%$; Fig. 7 ) are more accurate than the flood maps generated for the low-flow events $(F$ value of $63.3 \%$; Fig. 5). This finding is consistent with flood mapping results using the HEC-RAS hydraulic model in recently published work (Dey et al., 2019). They also showed that the median of $F$ values is higher with increasing flow. The maximum $F$ value of $92.6 \%$ occurs at NC during the medium flow (NC had the lowest overall $F$ value during the low-flow event). The sudden increase in $F$ value between the flood maps generated using low flow and medium flow at $\mathrm{NC}$ is due to the low-lying terrain near the river being simulated as flooded by both AutoRoute + ARPP and the USGS during the medium-flow event, thus reducing the overestimation and increasing the accuracy. Although flood maps for the medium- and high-flow events tend to have higher $F$ values, they also tend to have a bias to underestimate the flooded area ( $E$ values less than 1). The majority of the underestimation at the IN test site (Figs. 6 and 7) occurs where a tributary (Meadowbrook Creek) that is not accounted for in the AutoRoute simulation flows into the White River to the south and west of the town of Spencer.

The two test locations along the Deerfield River in Massachusetts (MC and MW) show consistent accuracy between the low, medium, and high flow rates. This region of Massachusetts has well-defined rivers and medium-to-high topographic relief. These features allow AutoRoute to better capture the riverbanks and floodplain, resulting in consistent accuracy ( $F$ values close to 100$)$ and minimal bias ( $E$ values close to 1$)$.

\subsection{Flood inundation mapping test using a high-resolution DEM}

Elevation datasets are used in flood mapping to define the topographic features (slopes, banks, levees, etc.) of the area being modeled; therefore the spatial resolution and vertical accuracy of the elevation datasets being used have a large impact on the accuracy of flood inundation maps being generated (Ali et al., 2015; Brandt and Lim, 2012; Cook and Merwade, 2009; Hsu et al., 2016). A thorough investigation of the impacts of various elevation datasets on the accuracy of flood inundation maps generated using AutoRoute+ARPP is outside the scope of this paper. However, a simple test is employed to determine if a high-resolution DEM $(\sim 3 \mathrm{~m})$ improves the flood inundation accuracy when using $\mathrm{Au}-$ toRoute + ARPP. The MS and NC sites had the most overestimation of flooding during the low-flow event when using $\mathrm{a} \sim 9 \mathrm{~m}$-resolution DEM and are therefore used in this test. A $1 / 9 \operatorname{arcsec}(\sim 3 \mathrm{~m})$ National Elevation Dataset (Gesch et al., 2002) elevation dataset replaces the $\sim 9 \mathrm{~m}$ elevation dataset. The NLCD was resampled to $1 / 9$ arcsec, but all other data remains the same from the previous tests. Figures 8 and 9 show the high-resolution flood inundation for low-, medium-, and high-flow events at NC (NC-3m) and MS (MS-3m), respectively. Table 3 shows the quantitative performance for flood inundation maps simulated using AutoRoute + ARPP compared to the USGS flood inundation maps. Table 3 and Figs. 5-8 show the flood results for NC and NC-3m are similar for each of the flow events. Even with the high-resolution DEM the model still simulates flooding in the low-lying terrain near the river in the low-flow event (Figs. 5 and 8), thus resulting in a high overestimation (high $E$ and $A_{\text {Over val- }}$ ues in Table 3$)$. Comparing the simulated area $\left(A_{\text {Sim }}\right)$ for the MS test site the model using $3 \mathrm{~m}$ DEM data produced a flood map having approximately half the area of the flood map using a $\sim 9 \mathrm{~m}$ DEM (Figs. 5 and 9). For the mediumand high-flow test cases the $A_{\text {Sim }}$ values were approximately $78 \%$ and $97 \%$, respectively, of the values when using a $\sim 9 \mathrm{~m}$ DEM. Use of higher resolution at the MS test site produced smaller $A_{\text {Sim }}$ values (Table 3 and Fig. 9), especially for smaller flood events. Although smaller $A_{\text {Sim }}$ values resulted in lower $A_{\text {Over }}$ values for MS-3m, they also resulted in higher $A_{\text {Under }}$ values which showed a bias of the model to underestimate the flooded area, and therefore the $F$ values did not improve when compared to the MS results. In general, the higher-resolution DEM did not substantially improve flood inundation results in NC or MS as expected.

Regardless of DEM resolution, inaccuracies in flood inundation results may be due to the use of constant Manning roughness coefficient values $\left(n_{i}\right)$ that are set solely based on land cover maps. Not only are roughness coefficients likely different even under the same land cover types, but the values of $n_{i}$ also vary with the depth of water (Ree and Palmer, 1949; Temple et al., 1987). In this study the low estimate of $n_{i}$ values used was based on Follum et al. (2017). However, that study did not include bathymetry estimation within the cross sections, and therefore a reexamination of the proper $n_{i}$ values to use within AutoRoute may be warranted. Another source of error may be the simple bathymetry estimation for each cross section. A more detailed bathymetry would affect the low-flow scenario the most but would likely improve the accuracy of flood inundation for all flow scenarios. 


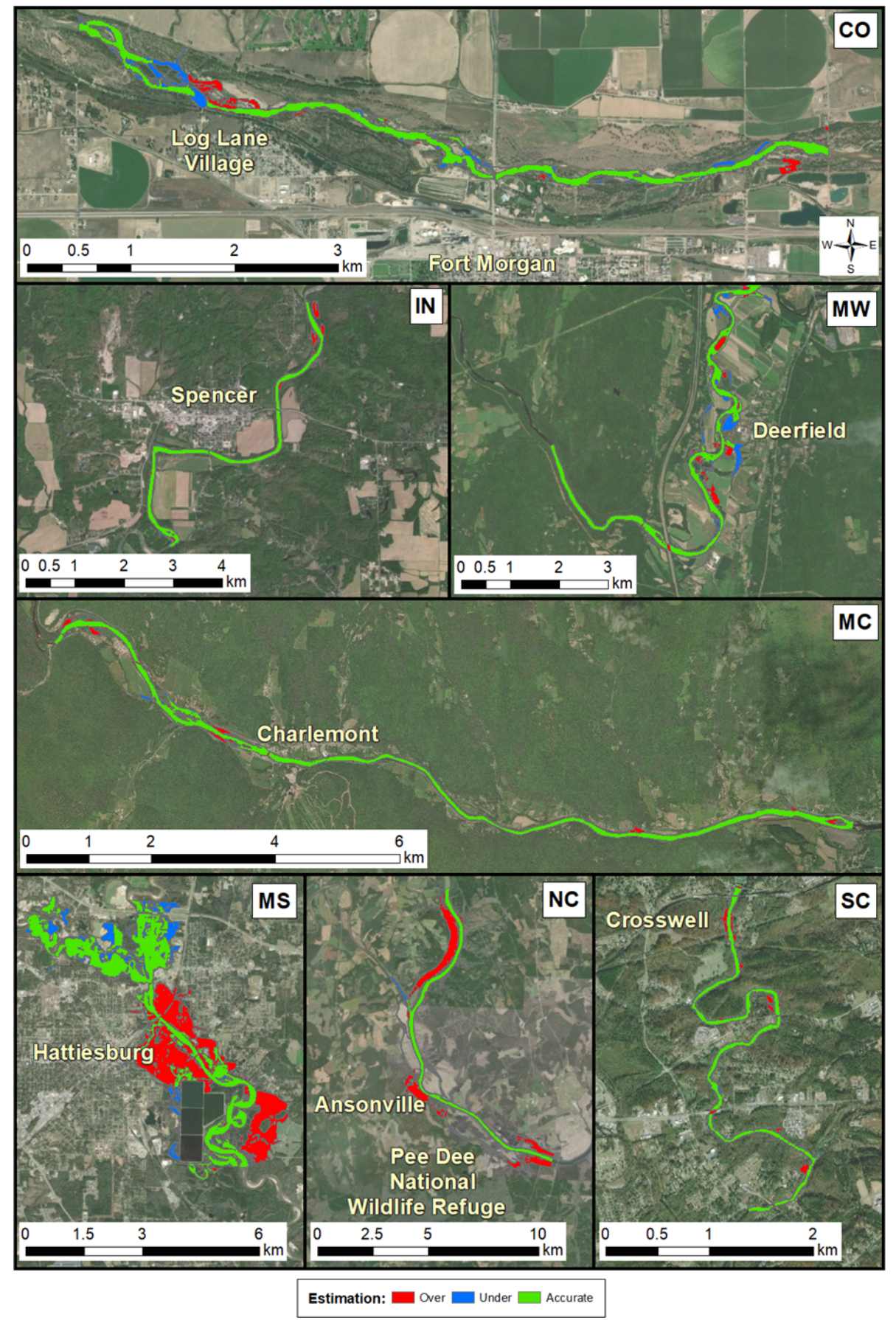

Figure 5. Flood map comparison between AutoRoute + ARPP simulations and USGS flood maps for low-flow events at the seven test sites. Areas shaded green (Accurate) indicate areas where AutoRoute + ARPP and the USGS flood maps agree. Areas shaded red (Over) indicate where only AutoRoute+ARPP simulates the area as flooded. Areas shaded blue (Under) indicate where only the USGS shows the area as flooded. Sources of the background imagery include ESRI, DigitalGlobe, Earthstar Geographics, CNES/Airbus DS, GeoEye, USDA FSA, USGS, Getmapping, Aerogrid, IGN, IGP, and the GIS user community. 


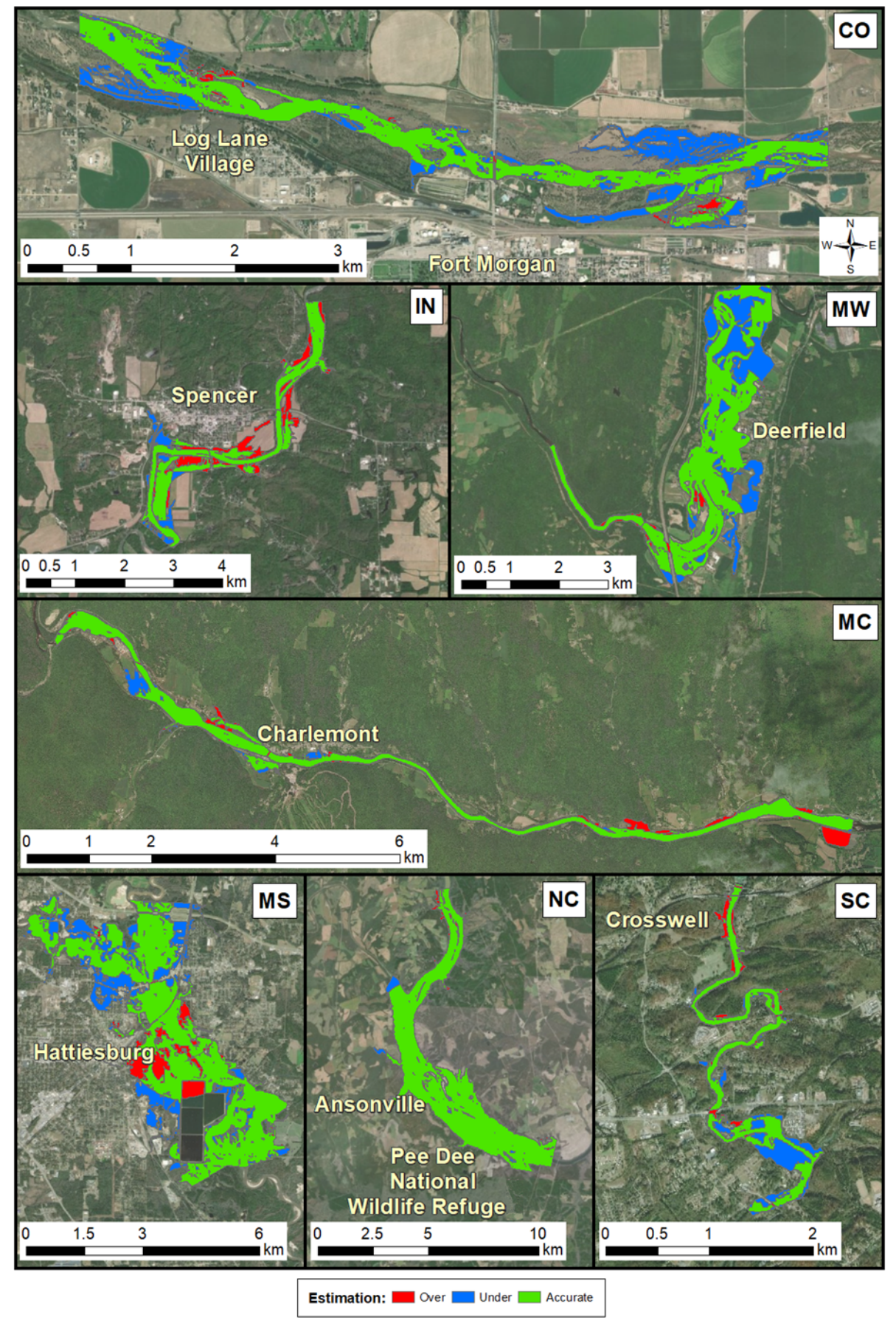

Figure 6. Flood map comparison between AutoRoute + ARPP simulations and USGS flood maps for medium-flow events at the seven test sites. Areas shaded green (Accurate) indicate areas where AutoRoute + ARPP and the USGS flood maps agree. Areas shaded red (Over) indicate where only AutoRoute + ARPP simulates the area as flooded. Areas shaded blue (Under) indicate where only the USGS shows the area as flooded. Sources of the background imagery include ESRI, DigitalGlobe, Earthstar Geographics, CNES/Airbus DS, GeoEye, USDA FSA, USGS, Getmapping, Aerogrid, IGN, IGP, and the GIS user community. 


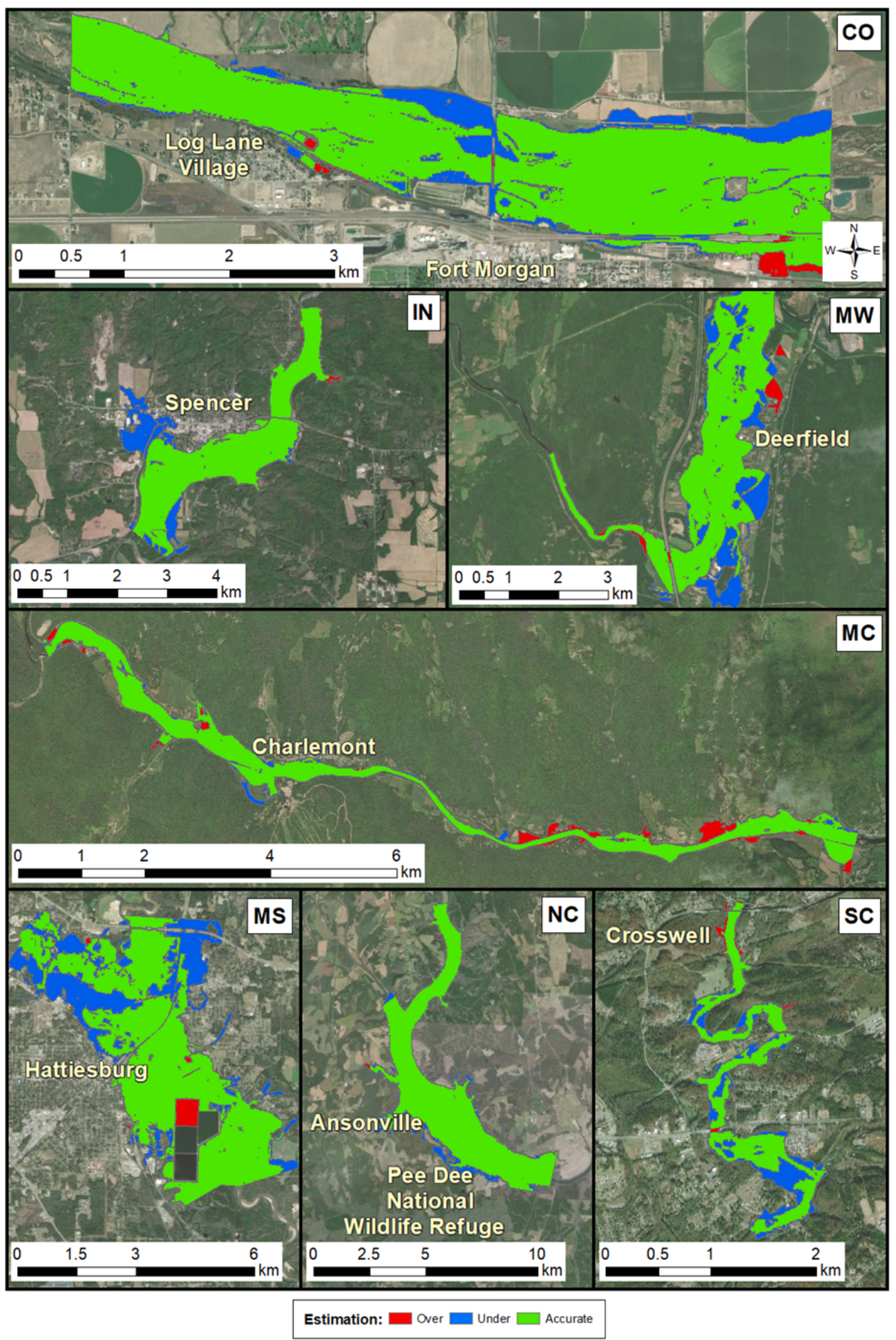

Figure 7. Flood map comparison between AutoRoute + ARPP simulations and USGS flood maps for high-flow events at the seven test sites. Areas shaded green (Accurate) indicate areas where AutoRoute + ARPP and the USGS flood maps agree. Areas shaded red (Over) indicate where only AutoRoute + ARPP simulates the area as flooded. Areas shaded blue (Under) indicate where only the USGS shows the area as flooded. Some of the overestimation in the MS model simulation occurs at water treatment ponds, which were not included in the USGS flood maps and can bias the results. Sources of the background imagery include ESRI, DigitalGlobe, Earthstar Geographics, CNES/Airbus DS, GeoEye, USDA FSA, USGS, Getmapping, Aerogrid, IGN, IGP, and the GIS user community. 


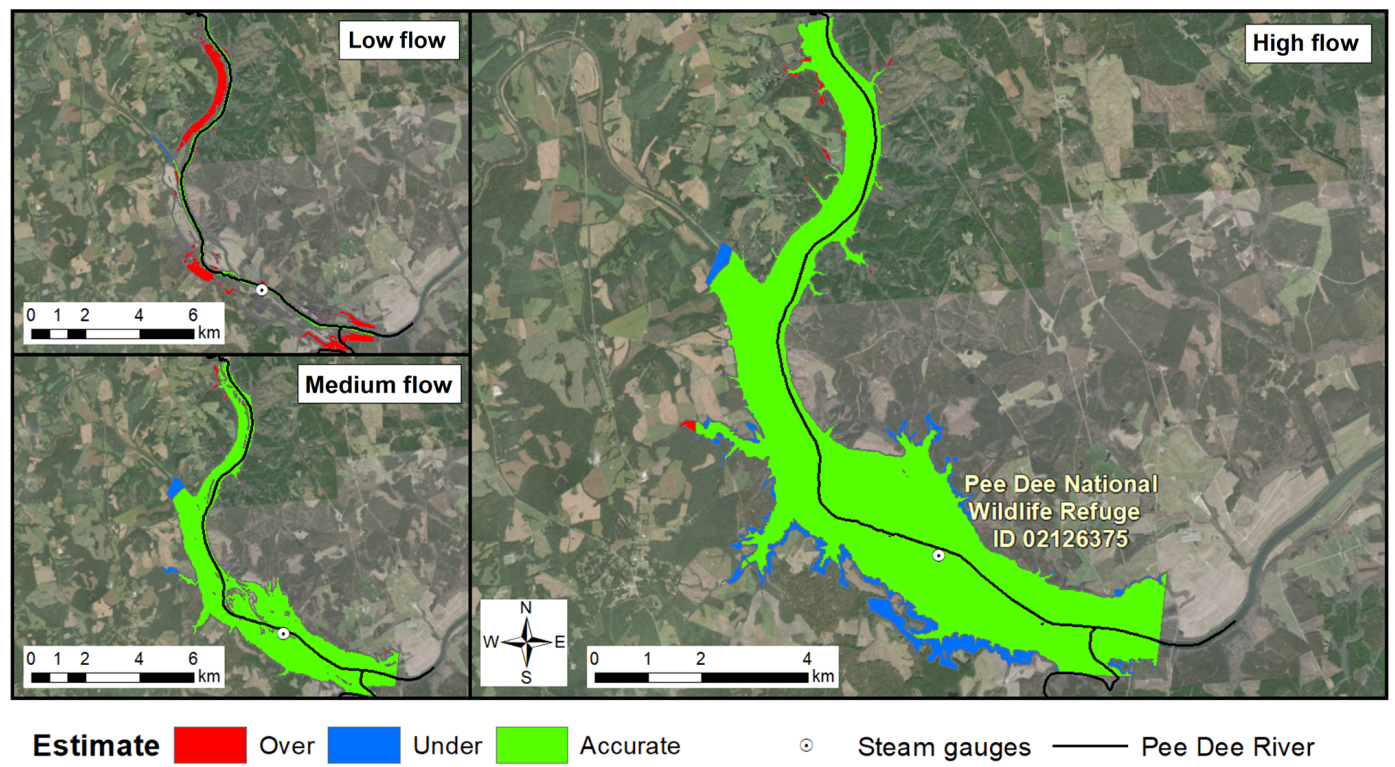

Figure 8. Pee Dee, NC (NC-3m), flood map comparison between AutoRoute + ARPP simulations using $\sim 3 \mathrm{~m}$ DEM and USGS flood maps. Areas shaded green (Accurate) indicate areas where AutoRoute + ARPP and the USGS flood maps agree. Areas shaded red (Over) indicate where only AutoRoute + ARPP simulates the area as flooded. Areas shaded blue (Under) indicate where only the USGS shows the area as flooded. Sources of the background imagery include ESRI, DigitalGlobe, Earthstar Geographics, CNES/Airbus DS, GeoEye, USDA FSA, USGS, Getmapping, Aerogrid, IGN, IGP, and the GIS user community.

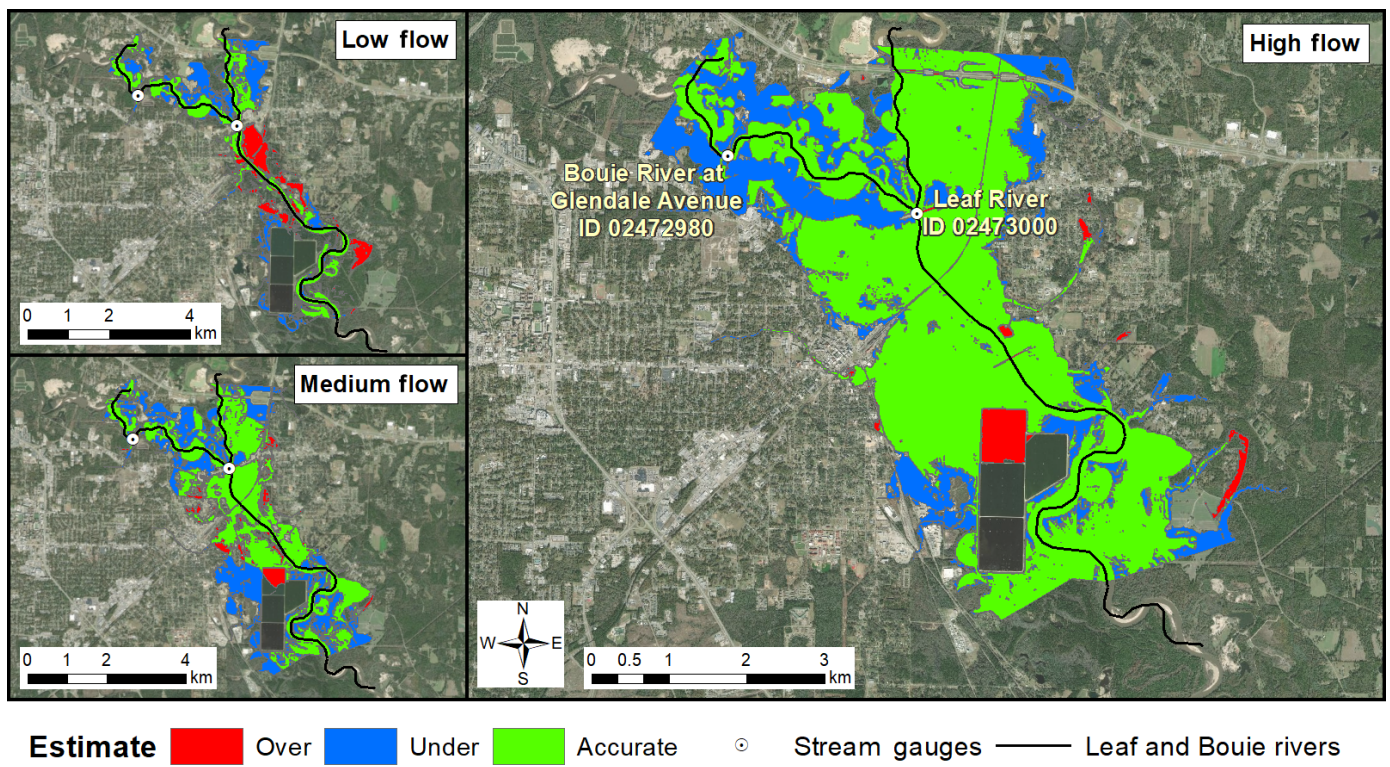

Figure 9. Hattiesburg, MS (MS-3m), flood map comparison between AutoRoute + ARPP simulations using $3 \mathrm{~m}$ DEM and USGS flood maps. Areas shaded green (Accurate) indicate areas where AutoRoute + ARPP and the USGS flood maps agree. Areas shaded red (Over) indicate where only AutoRoute + ARPP simulates the area as flooded. Areas shaded blue (Under) indicate where only the USGS shows the area as flooded. Some of the overestimation in the model simulation occurs at water treatment ponds, which were not included in the USGS flood maps and can bias the results. Sources of the background imagery include ESRI, DigitalGlobe, Earthstar Geographics, CNES/Airbus DS, GeoEye, USDA FSA, USGS, Getmapping, Aerogrid, IGN, IGP, and the GIS user community. 


\subsection{Simulation time}

On average, each flow event for each test case using the $\sim 9 \mathrm{~m}$ DEM took approximately $12 \mathrm{~s}$ to read all data (elevation, land cover, stream location, and flow rates) into memory, simulate flood depth results using AutoRoute, postprocess the flood depth results into raster flood maps using ARPP, and convert the raster flood maps into flood inundation polygons. For the high-resolution test locations (MS-3m and NC-3m) each test case took over $90 \mathrm{~s}$. However, all of the test cases were for relatively small areas, whereas the main reason to utilize a simplified hydraulics model such as AutoRoute is for computational efficiency when simulating flood inundation along thousands of river reaches at the regional to continental scale. Therefore, to compare computation times to the original AutoRoute methods described in Follum et al. (2017) the same domains in the Midwest (230 $000 \mathrm{~km}^{2}$ area) and Mississippi Delta (109500 $\mathrm{km}^{2}$ area) were simulated again using the methods described in this paper (AutoRoute + ARPP). Similar to Follum et al. (2017), the domains were discretized into thirty-nine $1^{\circ}$ by $1^{\circ}$ tiles (as defined by how USGS NED data are disseminated). Flow rates from Tavakoly et al. (2017) were once again used to define the peak flow in each river reach in the domain. The AutoRoute simulations in Follum et al. (2017) required approximately $20 \mathrm{~min}$ to simulate a $1^{\circ}$ by $1^{\circ}$ tile, compared to $17.5 \mathrm{~min}$ using the current version of AutoRoute. The current version of AutoRoute is more computationally efficient through the use of the Geospatial Data Abstraction Library (GDAL/OGR Contributors, 2019) for reading and writing data. The postprocessing procedure (i.e., GISPP) described in Follum et al. (2017) required approximately $15 \mathrm{~min}$ for each $1^{\circ}$ by $1^{\circ}$ tile. Postprocessing using ARPP to convert flood depth data to a flood depth raster and flood polygon takes approximately $3 \mathrm{~min}$. Overall, the current version of AutoRoute and the use of ARPP is over $40 \%$ more computationally efficient in simulating flood inundation maps.

The increased computational efficiency of AutoRoute and ARPP along with removing the requirement for ArcGIS software in postprocessing may allow for the AutoRoute model to more effectively be implemented on computational servers by CHL to provide flood and mobility assessments for OCONUS applications. These assessments will likely use SPT for streamflow data and be operated at the regional scale using a $1^{\circ}$ by $1^{\circ}$ spatial discretization. A further modification to improve computational efficiency may be to create a database of AutoRoute simulations for varying flow rates. When forecast flow rates become available the database could be used instead of an AutoRoute simulation to determine the depth within each stream cell. ARPP could then be used to generate the flood maps. This type of database could also provide flow-depth relationships to be used with the HAND method. Additionally, a production system could determine if streams within each modeling domain cross a specified bankfull streamflow threshold, and AutoRoute simulations would only occur if the streamflows for a given hydrometeorlogical forecast exceeded these bankfull thresholds. Either process may further improve the computational efficiency in creating production flood inundation maps.

\section{Conclusions}

The AutoRoute model is a simplified hydraulics model designed to quickly provide high-resolution flood inundation and mobility results at the regional to continental scale. The main purpose of this paper was to test the computational efficiency and accuracy of flood inundation maps generated by the AutoRoute model, with special consideration given to less-extreme flow events (i.e., low- and medium-flood events). Seven test sites were chosen to compare flood inundation maps using low, medium, and high flow rates. The seven test sites used a $\sim 9 \mathrm{~m}$ elevation dataset, and the locations correspond to existing USGS flood inundation studies and represent different regions within the US. The primary conclusions of the paper are as follows:

1. Implementation of a new postprocessing procedure improved the flood inundation accuracy of the AutoRoute model, especially when simulating low-flow events (average $F$ value increase of $17.5 \%$ when compared to previous postprocessing methods). Although the flood inundation results for low-flow events are comparable with other studies (average $F$ value of $63.3 \%$ ), the simulated flooding tends to be overestimated. Higher-flow scenarios tend to be more accurately simulated ( $F$ value for medium-flow events is $70.0 \%$ and average $F$ value for high-flow events is $77.5 \%$ ). Simplifications in estimating roughness coefficients, cross-section profiles (including bathymetry estimation), and the hydraulic simulation allow for AutoRoute to be computationally efficient but also may lead to errors in flood map simulation.

2. Recent updates to the input and output methods within AutoRoute model as well as the postprocessing procedure allow for the creation of flood inundation rasters ( $\sim 9 \mathrm{~m}$ resolution) and polygons in $20.5 \mathrm{~min}$ for a $1^{\circ}$ by $1^{\circ}$ area, as compared to $35 \mathrm{~min}$ in previous studies. Increased computational efficiency may allow for the AutoRoute model to more effectively be implemented in a production environment at the regional to continental scale.

3. Use of higher-resolution $(\sim 3 \mathrm{~m})$ elevation data within the AutoRoute model was also tested at two of the sites and did not significantly improve the accuracy of the flood inundation maps. One of the sites showed only minimal difference in flood inundation when using the higher-resolution elevation data. The second site had an 
almost $50 \%$ reduction in simulated area for the lowflow test case, which reduced the overestimation of the flooded area but also increased the underestimation of the flooded area. Use of the higher-resolution elevation datasets increased computation time by $750 \%$ compared to when the $\sim 9 \mathrm{~m}$ elevation dataset was used.

4. As has been found in other studies, AutoRoute performs best in areas with medium-to-high topographic relief, where one-dimensional flood models often perform well. Areas of minimal relief are more susceptible to backwater effects. AutoRoute physics do not account for such physical complexities, and model results tend to be less accurate. As such, flood inundation results from AutoRoute should be viewed as a first-order approximation, with the use of more detailed hydraulic models providing more actionable flood data.

The scope of this research was limited to small and medium inland rivers within the US. Several areas of future research were highlighted, including the need to better estimate roughness coefficients based on land cover and to account for change in roughness with flow depth. Improved elevation data and bathymetry estimation could increase the accuracy of both the flood inundation estimates and mobility assessment when using AutoRoute. Based on the recent work by Dey et al. (2019), different bathymetric methods could be implemented into AutoRoute for differing geomorphological conditions. Removal of outlier flood depth values will also improve the flood inundation estimation as well as the channel profiles that are used for mobility analysis. Use of a database system to store precomputed AutoRoute results could also increase computational efficiency and connect to other hydraulic models, such as HAND. Flood inundation models capable of quickly providing high-resolution flood maps have seen significant development over the past decade as regional- to continental-scale flow simulation models are becoming operationalized by the US Army, NOAA, and others. While the flow and flood inundation models continue to advance, the connection between the flood maps generated and the impacts to the population/environment need to become more fully developed.

Code and data availability. All elevation, land cover, streamflow, and USGS flood inundation data used in this paper are publicly available (see references throughout paper as well as Table 1). All output data and information regarding the AutoRoute model and AutoRoute postprocessing script (ARPP) are available by contacting the corresponding author.

Author contributions. All authors contributed to this article, with the order of the authors' names reflecting the size of their contribution. MLF is the lead developer of the AutoRoute model and AutoRoute postprocessing script (ARPP). For this paper he developed and ran all test cases, created several figures and tables, and contributed to most of the writing. RV contributed to the analysis of results, assisted in writing, and created several figures. AAT assisted in the analysis of results and assisted in the writing of the document. JLG assisted in the initial development of the ARPP as well as in the writing of the paper.

Competing interests. The authors declare that they have no conflict of interest.

Special issue statement. This article is part of the special issue "Advances in computational modelling of natural hazards and geohazards". It is a result of the Geoprocesses, geohazards - CSDMS 2018, Boulder, USA, 22-24 May 2018.

Acknowledgements. We would like to thank the funding organizations of this research. We would also like to thank Albert J. Kettner, Siddharth Saksena, and two anonymous reviewers for their insightful comments that helped improve this article.

Financial support. This project was supported by the Deputy Assistant Secretary of the Army for Research and Technology through the Engineer Research and Development Center's Military Engineering applied research work package title Austere Entry, the Geospatial Intelligence Directorate of the Marine Corps Intelligence Activity, and ERDC's collaborative research project supporting the NOAA National Water Center.

Review statement. This paper was edited by Albert J. Kettner and reviewed by Siddharth Saksena and two anonymous referees.

\section{References}

Afshari, S., Tavakoly, A. A., Rajib, M. A., Zheng, X., Follum, M. L., Omranian, E., and Fekete, B. M.: Comparison of new generation low-complexity flood inundation mapping tools with a hydrodynamic model, J. Hydrol., 556, 539-556, https://doi.org/10.1016/j.jhydrol.2017.11.036, 2018.

Ali, A. M., Solomatine, D. P., and Di Baldassarre, G.: Assessing the impact of different sources of topographic data on 1-D hydraulic modelling of floods, Hydrol. Earth Syst. Sci., 19, 631643, https://doi.org/10.5194/hess-19-631-2015, 2015.

Bates, P. D. and De Roo, A. P. J.: A simple raster-based model for flood inundation simulation, J. Hydrol., 236, 54-77, https://doi.org/10.1016/S0022-1694(00)00278-X, 2000.

Benedict, S. T., Caldwell, A. W., and Clark, J. M.: Flood-inundation maps for the Saluda River from Old Easley Bridge Road to Saluda Lake Dam near Greenville, South Carolina, US Geological Survey Scientific Investigations Map 3244, US Geological Survey, Reston, Virginia, USA, https://doi.org/10.3133/sim3244, 2013. 
Brandt, S. A. and Lim, N. J.: Importance of river bank and floodplain slopes on the accuracy of flood inundation mapping, in: River Flow 2012: Vol. 2, Proceedings of the International Conference on Fluvial Hydraulics, San 5-7 September 2012, José, Costa Rica, edited by: Murillo Muñoz, R. E., CRC Press/Balkema (Taylor \& Francis), Leiden, the Netherlands, 1015-1020, 2012.

Calenda, G., Mancini, C. P., and Volpi, E.: Distribution of the extreme peak floods of the Tiber River from the XV century, Adv. Water Resour., 28, 615-625, https://doi.org/10.1016/j.advwatres.2004.09.010, 2005.

Chow, V. T.: Open Channel Hydraulics, McGraw-Hill Book Company Inc, New York City, New York, 1959.

Cook, A. and Merwade, V.: Effect of topographic data, geometric configuration and modeling approach on flood inundation mapping, J. Hydrol., 377, 131-142, https://doi.org/10.1016/j.jhydrol.2009.08.015, 2009.

David, C. H., Maidment, D. R., Niu, G.-Y., Yang, Z.L., Habets, F., and Eijkhout, V.: River Network Routing on the NHDPlus Dataset, J. Hydrometeorol., 12, 913-934, https://doi.org/10.1175/2011JHM1345.1, 2011.

Dey, S., Saksena, S., and Merwade, V.: Assessing the Effect of Different Bathymetric Models on Hydraulic Simulation of Rivers in Data Sparse Regions, J. Hydrol., 575, 838-851, 2019.

Einstein, H. A.: The Hydraulic Cross Section Radius, Schweiz. Bauzeit., 103, 89-91, 1934.

ESRI: ArcGIS Desktop: Release 10, Environmental Systems Research Institute, Redlands, CA, 2011.

Follum, M. L.: AutoRoute Rapid Flood Inundation Model, Coastal and Hydraulics Engineering Technical Note ERDC/CHL CHETN-IV-88, US Army Engineer Research and Development Center, Coastal and Hydraulics Laboratory, Vicksburg, Mississippi, 2012.

Follum, M. L., Tavakoly, A. A., Niemann, J. D., and Snow, A. D.: AutoRAPID: A Model for Prompt Streamflow Estimation and Flood Inundation Mapping over Regional to Continental Extents, J. Am. Water Resour. Assoc., 53, 280-299, https://doi.org/10.1111/1752-1688.12476, 2017.

Follum, M. L., Gutenson, J. L., Wahl, M. D., Hunter, C. J., and Maldonado Linas, J. E.: Rapid Flood Inundation Modeling, Mil. Eng., 110, 37-38, 2018.

Follum, M. L., Paredez, J. M., Yeates, E. M., and Vera, R.: Utilizing Simple Large-Scale Flood Models to Prioritize Deployment of HEC-RAS 2D Models: Case Study of Navajo Nation Flood Inundation Maps, Flood Risk Manage. Newslett., 12, 4-7, 2019.

GDAL/OGR Contributors: GDAL/OGR Geospatial Data Abstraction Software Library, available at: https://gdal.org (last access: 14 February 2020), 2019.

Gesch, D. B., Oimoen, M., Greenlee, S., Nelson, C., Steuck, M., and Tyler, D.: The National Elevation Dataset, Photogram. Eng. Remote Sens., 68, 5-32, https://doi.org/10.1007/978-94-007-67690_1, 2002.

Homer, C., Dewitz, J., Yang, L., Jin, S., Danielson, P., Xian, G., Coulston, J., Herold, N., Wickham, J., and Megown, K.: Completion of the 2011 National Land Cover Database for the Conterminous United States - Representing a Decade of Land Cover Change Information, Photogramm. Eng. Remote Sens., 81, 345354, 2015.
Horizon Systems Corporation: National Hydrography Dataset Plus: Documentation, available at: http://www.horizon-systems. com/NHDPlus/NHDPlusV1_home.php (last access: 14 February 2020), 2007.

Horton, R. E.: Separate Roughness Coefficients for Channel Bottom and Sides, Eng. News Rec., 111, 652-653, 1933.

Hsu, Y.-C., Prinsen, G., Bouaziz, L., Lin, Y.-J., and Dahm, R.: An Investigation of DEM Resolution Influence on Flood Inundation Simulation, Proced. Eng., 154, 826-834, https://doi.org/10.1016/j.proeng.2016.07.435, 2016.

Kohn, M. S. and Patton, T. T.: Flood-inundation maps for the South Platte River at Fort Morgan, Colorado, US Geological Survey Scientific Investigations Report 20185114, US Geoglogical Survey, Reston, Virginia, USA, https://doi.org/10.3133/sir20185114, 2018.

Lehner, B. and Grill, G.: Global river hydrography and network routing: Baseline data and new approaches to study the world's large river systems, Hydrol. Process., 27, 2171-2186, https://doi.org/10.1002/hyp.9740, 2013.

Liu, Y. Y., Maidment, D. R., Tarboton, D. G., Zheng, X., and Wang, S.: A CyberGIS Integration and Computation Framework for High-Resolution Continental-Scale Flood Inundation Mapping, J. Am. Water Resour. Assoc., 54, 770-784, https://doi.org/10.1111/1752-1688.12660, 2018.

Lombard, P. J. and Bent, G. C.: Flood-inundation maps for the Deerfield River, Franklin County, Massachusetts, from the confluence with the Cold River tributary to the Connecticut River, US Geological Survey Scientific Investigations Report 2015-5104, US Geological Survey, Reston, Virginia, USA, https://doi.org/10.3133/sir20155104, 2015.

McEnery, J., Ingram, J., Duan, Q., Adams, T., and Anderson, L.: NOAA's Advanced Hydrologic Prediction Service, B. Am. Meteorol. Soc., 86, 375-386, https://doi.org/10.1175/BAMS-86-3375, 2005.

McKay, L., Bondelid, T., Dewald, T., Johnson, J., Moore, R., and Rea, A.: NHDPlus Version 2: User Guide, 2012.

McKinley, G. B., Mason, G. L., Follum, M. L., Jourdan, M. R., LaHatte, C. W., and Ellis, J.: A Route Corridor Flood Vulnerability System, Geotechnical and Structures Laboratory Technical Report ERDC/GSL TR-12-29, US Army Engineer Research and Development Center, Geotechnical and Structures Laboratory, Vicksburg, Mississippi, 2012.

Moore, M. R.: Development of a High-Resolution 1D/2D Coupled Flood Simulation of Charles City, Iowa, MS Thesis, University of Iowa, Iowa City, Iowa, USA, 2011.

Nystrom, E. A.: Flood-inundation maps for the White River at Spencer, Indiana, US Geological Survey Scientific Investigations Map 3251, US Geological Survey, available at: https://pubs.usgs. gov/sim/3251 (last access: 14 February 2020), 2013.

Ree, W. and Palmer, V.: Flow of water in channels protected by vegetative linings, No. 967, US Dept. of Agriculture, Washington, D.C., 1949.

Smith, D. G. and Wagner, C. R.: Hydraulic model and floodinundation maps developed for the Pee Dee National Wildlife Refuge, North Carolina, US Geological Survey Scientific Investigations Report 2015-5137, US Geological Survey, Reston, Virginia, USA, https://doi.org/10.3133/sir20155137, 2016. 
Snow, A. D.: A New Global Forecasting Model to Produce HighResolution Stream Forecasts, MS Thesis, Brigham Young University - Provo., Brigham, 2015.

Snow, A. D., Christensen, S. D., Swain, N. R., Nelson, E. J., Ames, D. P., Jones, N. L., Ding, D., Noman, N. S., David, C. H., Pappenberger, F., and Zsoter, E.: A High-Resolution NationalScale Hydrologic Forecast System from a Global Ensemble Land Surface Model, J. Am. Water Resour. Assoc., 52, 950-964, https://doi.org/10.1111/1752-1688.12434, 2016.

Storm, J. B.: An expanded model - Flood-inundation maps for the Leaf River at Hattiesburg, Mississippi, US Geological Survey Scientific Investigations Map 3300, US Geological Survey, Reston, Virginia, USA, https://doi.org/10.3133/sim3228, 2014.

Tavakoly, A. A., Snow, A. D., David, C. H., Follum, M. L., Maidment, D. R., and Yang, Z. L.: Continental-Scale River Flow Modeling of the Mississippi River Basin Using High-Resolution NHDPlus Dataset, J. Am. Water Resour. Assoc., 53, 258-279, https://doi.org/10.1111/1752-1688.12456, 2017.

Tayefi, V., Lane, S. N., Hardy, R. J., and Yu, D.: A comparison of one- and two-dimensional approaches to modelling flood inundation over complex upland floodplains, Hydrol. Process., 21, 3190-3202, https://doi.org/10.1002/hyp.6523, 2007.

Temple, D. M., Robinson, K. M., Ahring, R. M., and Davis, A. G.: Stability design of grass-lined open channels, USDA Agricultural Handbook No. 667, USDA, Washington, D.C., 1987.
USACE - US Army Corps of Engineers: HEC-RAS River Analysis System, hydraulic reference manual, Davis, California, USA 2010.

USACE - US Army Corps of Engineers: HEC-RAS River Analysis System, hydraulic reference manual, Davis, California, USA, 2016.

Wahl, M. D., Follum, M. L., Snow, A. D., and Tavakoly, A. A.: Developing Hydrologic Awareness, Military Eng., 108, 65-66, 2016.

Wing, O. E. J., Bates, P. D., Sampson, C. C., Smith, A. M., Johnson, K. A., and Erickson, T. A.: Validation of a $30 \mathrm{~m}$ resolution flood hazard model of the conterminous United States, Water Resour Res., 53, 7968-7986, https://doi.org/10.1002/2017WR020917, 2017.

Zheng, X., Maidment, D., Liu, Y., Tarboton, D. G., and Lin, P.: From Forecast Hydrology to Real-Time Inundation Mapping at Continental Scale, in: AGU Fall Meeting, available at: https://agu.confex.com/agu/fm16/meetingapp.cgi/Paper/ 186012 (last access: 14 February 2020), 2016.

Zheng, X., Maidment, D. R., Tarboton, D. G., Liu, Y. Y., and Passalacqua, P.: GeoFlood: Large-Scale Flood Inundation Mapping Based on High-Resolution Terrain Analysis, Water Resour. Res., 54, 10013-10033, https://doi.org/10.1029/2018WR023457, 2018. 